\title{
Terrorism in Australia: factors associated with perceived threat and incident-critical behaviours
}

\author{
Garry Stevens*1, Kingsley Agho ${ }^{1}$, Melanie Taylor ${ }^{1}$, Margo Barr ${ }^{2}$, \\ Beverley Raphael ${ }^{1}$ and Louisa Jorm ${ }^{2}$
}

Address: ${ }^{1}$ School of Medicine, University of Western Sydney, Building EV, Parramatta Campus, Locked Bag 1797, Penrith, NSW, DC1797, Australia and ${ }^{2}$ Centre for Epidemiology and Research, Population Health Division, New South Wales Department of Health, Locked Bag 961, North Sydney, New South Wales, 2059, Australia

Email: Garry Stevens* - g.stevens@uws.edu.au; Kingsley Agho - k.agho@uws.edu.au; Melanie Taylor - melanie.taylor@uws.edu.au; Margo Barr - meyes@doh.health.nsw.gov.au; Beverley Raphael - b.raphael@uws.edu.au; Louisa Jorm - louisa.jorm@uws.edu.au

* Corresponding author

Published: 27 March 2009

BMC Public Health 2009, 9:91 doi:10.1/86/147|-2458-9-91
Received: 20 November 2008

Accepted: 27 March 2009

This article is available from: http://www.biomedcentral.com/I47I-2458/9/9I

(C) 2009 Stevens et al; licensee BioMed Central Ltd.

This is an Open Access article distributed under the terms of the Creative Commons Attribution License (http://creativecommons.org/licenses/by/2.0), which permits unrestricted use, distribution, and reproduction in any medium, provided the original work is properly cited.

\begin{abstract}
Background: To help improve incident preparedness this study assessed socio-demographic and socio-economic predictors of perceived risk of terrorism within Australia and willingness to comply with public safety directives during such incidents.
\end{abstract}

Methods: The terrorism perception question module was incorporated into the New South Wales Population Health Survey and was completed by a representative sample of 2,08I respondents in early 2007. Responses were weighted against the New South Wales population.

Results: Multivariate analyses indicated that those with no formal educational qualifications were significantly more likely $(\mathrm{OR}=2.10,95 \% \mathrm{Cl}: \mathrm{I} .32-3.35, \mathrm{p}<0.00 \mathrm{I})$ to think that a terrorist attack is very or extremely likely to occur in Australia and also more likely $(\mathrm{OR}=3.62,95 \% \mathrm{Cl}: 2.25-5.83$, $\mathrm{P}$ $<0.00 \mathrm{I})$ to be very or extremely concerned that they or a family member would be directly affected, compared to those with a university-level qualification. Speaking a language other than English at home predicted high concern (very/extremely) that self or family would be directly affected $(\mathrm{OR}=3.02,95 \% \mathrm{Cl}: 2.02-4.53, \mathrm{p}<0.00 \mathrm{I})$ and was the strongest predictor of having made associated changes in living $(\mathrm{OR}=3.27,95 \% \mathrm{Cl}: 2.17-4.93, \mathrm{p}<0.00 \mathrm{I})$. Being female predicted willingness to evacuate from public facilities. Speaking a language other than English at home predicted low willingness to evacuate.

Conclusion: Low education level is a risk factor for high terrorism risk perception and concerns regarding potential impacts. The pattern of concern and response among those of migrant background may reflect secondary social impacts associated with heightened community threat, rather than the direct threat of terrorism itself. These findings highlight the need for terrorism risk communication and related strategies to address the specific concerns of these sub-groups as a critical underpinning of population-level preparedness. 


\section{Background}

Understanding how the public perceives the risk of a terrorist attack, and are likely to respond, are key elements of event preparation $[1,2]$. Identifying sub-populations at particular risk will allow health authorities to promote awareness of risk related issues and key behaviours critical to the response of these groups [3].

The September 11 attacks evoked high levels of distress within the U.S. population and showed that intense psychological impacts were not restricted to the immediately affected region [4]. Six months after the incident, two independent population surveys found that $40 \%-50 \%$ of U.S. adults feared for the direct safety of themselves and family members in relation to terrorist attacks $[5,6]$. In affected communities, perceived high risk of further attacks is linked to behaviour changes such as avoiding 'high risk' places, restricting travel or increased substance use [7-10]. At the same time, pre-event risk communication initiatives have been shown to reduce some reactive behaviour changes, even at the population level [7].

Demographic and socio-economic factors found to predict higher terrorism risk perception and distress include female gender, being a member of a visible minority ethnic or religious group, older age and having lower levels of education or income $[5,7,11,12]$. Some of these subgroups may be exposed to increased risk through their own reactive behaviours, such as evacuation in threat situations against official advice or increased drug and alcohol use over time $[9,12]$.

Less is known about the factors mediating threat perception in countries without recent terrorism but which conceivably face such risks. In 2004, only $20 \%$ of Canadians felt such attacks would occur in their country; despite its common border with the U.S. and reported high levels of terrorist activity within Canada at the time of the survey $[13,14]$. Older respondents and those with higher education or born outside Canada were significantly more likely to view these threats as being high. Despite lower levels of concern overall, most Canadians were extremely willing to perform procedures such as evacuation, quarantine or vaccination if asked to do so by government authorities.

Australia has not experienced recent domestic terrorism but its citizens have been affected by major bombings in Bali in 2002 and 2005 and related events, such as being named as a terrorist target by groups such as $\mathrm{Al}$ Qaeda [15]. In this context, identification of groups at heightened risk due to the threat of terrorism will assist the development of targeted risk communication and other preparedness initiatives. The aim of this study was to assess socio-demographic and socio-economic factors associated with terrorism risk perception, behaviour change and an incident-critical response; evacuation compliance in the context of imminent threat.

\section{Methods}

A background literature search was conducted to identify existing tools with items that assessed perceptions of terrorist attack, notably; likelihood, effects on self or family (perceived risk and vulnerability), terrorism-related changes in living and compliance with government safety directives. A study by Canadian researchers on perceptions and anticipated responses to terrorism was a primary reference for the current survey $[13,14]$. Questions on threat likelihood, effect on family, and evacuation compliance were adapted, with permission, by the current authors.

\section{Administration}

The terrorism perception module was administered as part of the NSW Population Health Survey using the NSW Health Survey program Computer Assisted Telephone Interview (CATI) system between 22 January and 31 March 2007 [16]. The target population was all residents aged 16 years and over, living in NSW and stratified by geographical region.

Trained interviewers at the Health Survey Program CATI facility contacted households using random digit dialling to conduct the interviews. At initial contact, one person from each household was selected, via a randomly generated birth order selection, for inclusion in the study. This procedure is described in detail elsewhere [17]. Up to 7 calls were made to establish initial contact with a household and 5 calls were made in order to contact a selected respondent.

A total of 2,081 state residents completed the terrorism module. The response rate was $65 \%$. The survey questions were validated and the corresponding kappa values for the indicators ranged between 0.27 and 0.64 in the second field test. The demographic profile of the weighted survey population was comparable with the Australian population. This is reported elsewhere [17].

\section{Measurements}

The question set was established following field testing for test-retest reliability using the protocol of the New South Wales Health Survey. A detailed description of its application in the current study is presented elsewhere [16]. The field test and final modules, survey protocols and informed consent procedures were approved by the University of Western Sydney and NSW Population Health and Health Services ethics committees for approval prior to use. 
The five-point Likert-scale responses to perceptions of terrorism threat and evacuation willingness were dichotomised. Responses of "don't know" or refused were excluded. The definitions of terrorist attack likely to occur, concern for self/family, changed way of living and evacuation indicators used in this study were as follows:

- Terrorist attack likely: Indicates proportion of respondents who thought it was 'very' or 'extremely' likely that a terrorist attack will occur in Australia.

- Concern for self/family: Proportion of respondents who would be 'very' or 'extremely' concerned that they or a family member would be directly affected if a terrorist attack occurred in Australia.

- Changed way of living: Proportion of respondents who had changed the way they live their lives 'a little', 'moderately', 'very' or 'extremely' because of the possibility of the terrorist attack.

- Combined indicator (1): Terrorist attack likely + Concern for self/family

- Combined indicator (2): Terrorist attack likely + Concern for self/family + Changed way of living.

- Willingness to evacuate home: Proportion of respondents 'very' or 'extremely' willing to evacuate home in the event of an emergency situation such as a terrorist attack.

- Willingness to evacuate workplace or public facility: Proportion of respondents 'very' or 'extremely' willing to evacuate their workplace or a public facility in the event of an emergency situation such as a terrorist attack.

- Combined indicator (3): Willingness to evacuate home + office/public facility

The demographic and socio-economic factors that were examined for their associations with threat perception and willingness to evacuate were: age, marital status; having children less than 16 years of age; residential location (urban or rural, as determined by Area Health authority); being born in Australia; speaking a language other than English at home; highest educational qualification; household income, self-rated health status and current psychological distress, as measured by the 10-item Kessler Psychological Distress Scale (K10). Scores on the K10 range from 10-50, with $\geq 22$ considered 'high' psychological distress [18].

\section{Data analysis}

Data analysis was performed using the "SVY" commands of STATA version 9.2 (Stata Corp, College Station, TX, USA), which allowed for adjustments for sampling weights.

The key indicators of terrorist attack likely, concern, changed way of living and evacuation willingness were examined by socio-demographic and socio-economic factors (see Measurements section). Multiple logistic regression analysis using a backward stepwise model was used to examine risk factors for the eight indicators of interest i.e. five single indicators (terrorism likely, concern, changed way of living, evacuate home and evacuate workplace/public facility) and the three combined indicators noted above.

The survey data were weighted to adjust for the probability of selection and for differing non-response rates among males and females and different age groups. All variables with statistical significance of $p \leq 0.05$ were retained in the final model.

\section{Results}

Overall, 30.3\% thought a terrorist attack in Australia was very or extremely likely, $42.5 \%$ were very or extremely concerned that they or their family would be directly affected by such an incident and $26.4 \%$ had changed the way they live their life due to the possibility of a terrorist attack. Figure 1 shows the percentage of respondents, by language spoken at home i.e. English or a language other than English (LOTE), who perceived a terrorist attack to be likely, had high concerns for self/family or who had changed the way they lived their lives due the perceived risk of terrorism.

The significant, adjusted Odd Ratios (OR) observed in the multivariate analysis are presented in Table 1 . These results showed that Australians with no formal educational qualifications were significantly more likely ( $\mathrm{OR}=$ 2.10, 95\% Confidence Interval (CI):1.32-3.35, p < 0.001) to report that they perceived a terrorist attack was extremely or very likely to occur, compared to those with university level qualifications. Respondents who were never married were significantly less likely to perceive a terrorist attack as extremely or very likely, compared with married respondents $(\mathrm{OR}=0.51,95 \% \mathrm{CI}: 0.35-0.73, \mathrm{p}<$ $0.001)$.

Respondents living in urban health districts were significantly more likely to be very or extremely concerned that they or their family would be directly affected in the event of a terrorist attack, compared to those from rural health districts $(\mathrm{OR}=0.77,95 \% \mathrm{CI}: 0.60-0.99, \mathrm{p}=0.045)$. Those who spoke a language other than English at home were 


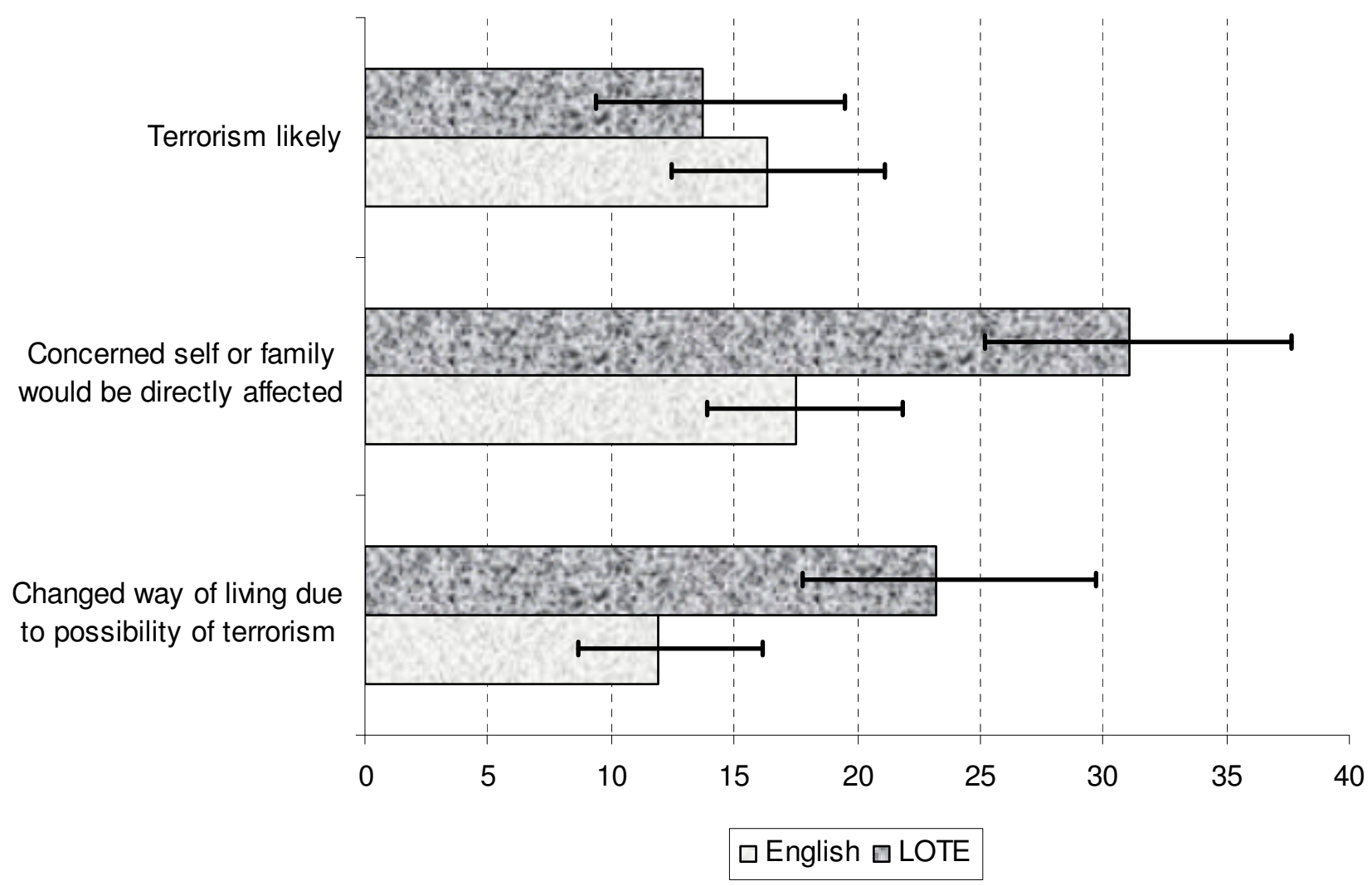

Figure I

Percentage of respondents, by language group (English or language other than English, 'LOTE'), perceiving terrorist attack likely, concerned and changed way of living.

significantly more likely to be concerned that they or a family member would be directly affected in the event of an attack, compared to respondents who spoke only English at home $(\mathrm{OR}=3.02,95 \% \mathrm{CI}: 2.02-4.53, \mathrm{p}<0.001)$. Respondents with no formal educational qualifications were significantly more likely (OR = 3.62, 95\%CI:2.25$5.83, \mathrm{p}<0.001)$ to be concerned that they/family members would be directly affected, than those with university level qualifications. Younger adults (25-34 years) were significantly more likely (OR $=2.44,95 \% \mathrm{CI}: 1.36-4.38, \mathrm{p}$ $=0.003$ ) to have high levels of concern for self/family in the event of an attack than the those in the youngest group surveyed (16-24 years).

Australians who spoke a language other than English at home were significantly more likely to have made changes in the way they lived due to the possibility of terrorism, compared to those who spoke English at home $(\mathrm{OR}=$ $3.27,95 \% \mathrm{CI}: 2.17-4.93, \mathrm{p}<0.001)$. Those with no formal educational qualifications were significantly more likely $(\mathrm{OR}=2.27,95 \% \mathrm{CI}: 1.36-3.77, \mathrm{p}=0.002)$ to have made such changes, compared to those with university level qualifications. Older respondents were significantly less likely to have changed the way they lived due to terrorism risk, notably; those 65-74 years of age $(\mathrm{OR}=0.48$, 95\%CI:0.23-0.99, $\mathrm{p}<0.048)$ and those 75 years or older (OR $=0.21,95 \% \mathrm{CI}: 0.09-0.48, \mathrm{p}<0.001)$ compared to younger respondents (16-24 years).

With regard to the combined indicators, respondents with no formal education were significantly more likely to report high terrorism likelihood and high concern that they/family members would be directly affected should such an event occur (combined indicator 1) compared to those with university level qualifications $(\mathrm{OR}=4.52$, 95\%CI:2.63-7.75, p $<0.001)$. Two groups were significantly more likely to perceive a terrorist attack as likely, be concerned that self/family would be affected and to have also made changes in the way they lived due to this possibility (combined indicator 2); those living in urban health areas, compared to those in rural health areas $(\mathrm{OR}=0.64$, 95\%CI:0.42-0.97, $\mathrm{p}=0.038$ ) and those with no formal 
Table I: Factors associated with terrorist attack likely, concern, changed way of living, willingness to evacuate and combined indicators - adjusted Odds Ratios

\begin{tabular}{|c|c|c|c|c|}
\hline \multirow{2}{*}{$\begin{array}{l}\text { Outcome variable } \\
\text { Terrorist attack likely }\end{array}$} & \multirow{2}{*}{$\begin{array}{l}\text { Independent variable } \\
\text { Highest formal qualification }\end{array}$} & \multirow[t]{2}{*}{ OR } & \multicolumn{2}{|c|}{$95 \% \mathrm{Cl}$} \\
\hline & & & & \\
\hline & University degree/equivalent & 1.00 & & \\
\hline & TAFE certificate/Diploma & 1.44 & 0.97 & 2.12 \\
\hline & High school certificate & 1.07 & 0.69 & 1.66 \\
\hline & School certificate & 1.59 & 1.10 & 2.31 \\
\hline & None & 2.10 & 1.32 & 3.35 \\
\hline & Marital status & & & \\
\hline & Married & 1.00 & & \\
\hline & Widowed & 0.80 & 0.55 & 1.18 \\
\hline & separated/divorced & 1.40 & 0.97 & 2.03 \\
\hline & Never married & 0.51 & 0.35 & 0.73 \\
\hline \multirow[t]{20}{*}{ Concerned self or family directly affected } & Location & & & \\
\hline & Urban & 1.00 & & \\
\hline & Rural & 0.77 & 0.60 & 0.99 \\
\hline & Age category & & & \\
\hline & $16-24$ & 1.00 & & \\
\hline & $25-34$ & 2.44 & 1.36 & 4.38 \\
\hline & $35-44$ & 1.10 & 0.63 & 1.92 \\
\hline & $45-54$ & 1.77 & 1.06 & 2.97 \\
\hline & $55-64$ & 1.69 & 1.01 & 2.81 \\
\hline & $65-74$ & 2.01 & 1.22 & 3.33 \\
\hline & $75+$ & 2.04 & 1.17 & 3.57 \\
\hline & Speak language other than English & & & \\
\hline & No & 1.00 & & \\
\hline & Yes & 3.02 & 2.02 & 4.53 \\
\hline & Highest formal qualification & & & \\
\hline & University degree/equivalent & 1.00 & & \\
\hline & TAFE certificate/Diploma & 1.57 & 1.07 & 2.30 \\
\hline & High school certificate & 1.88 & 1.23 & 2.86 \\
\hline & School certificate & 2.75 & 1.90 & 3.98 \\
\hline & None & 3.62 & 2.25 & 5.83 \\
\hline \multirow[t]{22}{*}{ Changed way of living } & Age category & & & \\
\hline & $16-24$ & 1.00 & & \\
\hline & $25-34$ & 0.78 & 0.38 & 1.60 \\
\hline & $35-44$ & 0.80 & 0.40 & 1.59 \\
\hline & $45-54$ & 0.83 & 0.41 & 1.68 \\
\hline & $55-64$ & 0.58 & 0.29 & 1.18 \\
\hline & $65-74$ & 0.48 & 0.23 & 0.99 \\
\hline & $75+$ & 0.21 & 0.09 & 0.48 \\
\hline & Speak language other than English & & & \\
\hline & No & 1.00 & & \\
\hline & Yes & 3.27 & 2.17 & 4.93 \\
\hline & Highest formal qualification & & & \\
\hline & University degree/equivalent & 1.00 & & \\
\hline & TAFE certificate/Diploma & 1.45 & 0.94 & 2.23 \\
\hline & High school certificate & 1.62 & 1.00 & 2.63 \\
\hline & School certificate & 1.77 & 1.15 & 2.71 \\
\hline & None & 2.27 & 1.36 & 3.77 \\
\hline & Marital status & & & \\
\hline & Married & 1.00 & & \\
\hline & Widowed & 1.47 & 0.94 & 2.29 \\
\hline & separated/divorced & 1.04 & 0.69 & 1.55 \\
\hline & Never married & 0.49 & 0.30 & 0.81 \\
\hline \multirow[t]{3}{*}{ Terrorism likely + concerned for self/family } & Highest formal qualification & & & \\
\hline & University degree/equivalent & 1.00 & & \\
\hline & TAFE certificate/Diploma & 1.61 & 0.96 & 2.69 \\
\hline
\end{tabular}


Table I: Factors associated with terrorist attack likely, concern, changed way of living, willingness to evacuate and combined indicators - adjusted Odds Ratios (Continued)

\begin{tabular}{|c|c|c|c|c|}
\hline & High school certificate & 1.63 & 0.95 & 2.80 \\
\hline & School certificate & 2.68 & 1.68 & 4.27 \\
\hline & None & 4.52 & 2.63 & 7.75 \\
\hline \multirow[t]{9}{*}{ Terrorism likely + concerned + changed way of living } & Location & & & \\
\hline & Urban & 1.00 & & \\
\hline & Rural & 0.64 & 0.42 & 0.97 \\
\hline & Highest formal qualification & & & \\
\hline & University degree/equivalent & 1.00 & & \\
\hline & TAFE certificate/Diploma & 1.51 & 0.69 & 3.33 \\
\hline & High school certificate & 1.32 & 0.59 & 2.95 \\
\hline & School certificate & 2.79 & 1.43 & 5.45 \\
\hline & None & 3.83 & 1.73 & 8.48 \\
\hline \multirow[t]{3}{*}{ Willing to evacuate home } & Employed & & & \\
\hline & No & 1.00 & & \\
\hline & Yes & 1.37 & 1.06 & 1.79 \\
\hline \multirow[t]{12}{*}{ Willing to evacuate office/public facility } & Gender & & & \\
\hline & Male & 1.00 & & \\
\hline & Female & 1.80 & 1.27 & 2.56 \\
\hline & Speak language other than English & & & \\
\hline & No & 1.00 & & \\
\hline & Yes & 0.46 & 0.27 & 0.79 \\
\hline & Highest formal qualification & & & \\
\hline & University degree/equivalent & 1.00 & & \\
\hline & TAFE certificate/Diploma & 0.74 & 0.39 & 1.42 \\
\hline & High school certificate & 0.53 & 0.27 & 1.02 \\
\hline & School certificate & 0.45 & 0.25 & 0.82 \\
\hline & None & 0.58 & 0.29 & 1.16 \\
\hline \multirow[t]{6}{*}{ Willingness to evaluate home + office/public facility } & Employed & & & \\
\hline & No & 1.00 & & \\
\hline & Yes & $\mid .51$ & 1.16 & 1.95 \\
\hline & Gender & & & \\
\hline & Male & 1.00 & & \\
\hline & Female & 1.46 & 1.12 & 1.90 \\
\hline
\end{tabular}

Note: Independent variables adjusted for are; age, marital status; have children less than 16 years; location (urban/rural); born in Australia; employment, speak a language other than English at home (LOTE); highest educational qualification; household income, self-rated health status and psychological distress, measured using the KiO.

educational qualifications, compared to those with university level qualifications $(\mathrm{OR}=3.83,95 \% \mathrm{CI}: 1.73-8.48$, $\mathrm{p}=0.001)$.

The multivariate analysis also revealed that employed people were significantly more likely $(\mathrm{OR}=1.37$, 95\%CI:1.06-1.79, $\mathrm{p}=0.018$ ) to report being extremely or very willing to evacuate their home during a terrorismrelated emergency than unemployed respondents. Females were significantly more likely to report high willingness to evacuate offices or public places $(\mathrm{OR}=1.80$, $95 \% \mathrm{CI}: 1.27-2.56, \mathrm{p}=0.001$ ), while two groups were less likely to do so; LOTE respondents $(\mathrm{OR}=0.46$, 95\%CI:0.27-0.79, p = 0.005) and those with a middle high school level qualification (school certificate) compared to those with university level qualifications $(\mathrm{OR}=$
$0.45,95 \%$ CI:0.25-0.82, $\mathrm{p}=0.009)$. Willingness to evacuate homes and offices/public places (combined indicator $3)$ was predicted by female gender $(\mathrm{OR}=1.46$, $95 \% \mathrm{CI}: 1.12-1.90, \mathrm{p}=0.018)$ and being currently employed $(\mathrm{OR}=1.51,95 \% \mathrm{CI}: 1.16-1.95, \mathrm{p}=0.018)$.

\section{Discussion}

Although there have been no recent acts of terrorism within Australia, the current analysis highlights notable differences between demographic and socio-economic sub-groups regarding perceived terrorism likelihood, vulnerability and reactive changes in living. Significantly associated risk factors in relation to these variables were cultural/linguistic minority group status (i.e. speaking a language other than English at home), having no formal educational qualifications, being middle aged (45-54 
years) or an urban resident. Younger age (16-24 years) predicted significantly lower levels of concern and perceived likelihood.

Females and employed respondents expressed the greatest willingness to follow evacuation directives, while having lower level educational qualifications (i.e. middle high school) or speaking a language other than English at home were risk factors for low willingness to evacuate.

The current results indicate that low education level is a risk factor for high terrorism risk perception and concerns regarding potential impacts. This result contrasts with those of a recent Canadian population study where those with college level education perceived the greatest threat of terrorism [14]. This result may be a function of the time difference between surveys (2004 and 2007) or the different geo-political forces in these countries. However, low levels of formal education may also limit critical appraisal of conveyed terrorism risks, including event probability and the socio-political factors influencing threat construal [19]. Alternatively, these individuals may perceive that they have less resources available (material and social) in emergency situations and therefore have more invested in maintaining concern and vigilance; in order to be prepared [12]. The finding that those with no formal educational qualifications had a high odds ratio for the combined indicator attack likely/concern for self and family ( OR = 4.52) may be seen to offer particular support for this latter view.

High levels of concern were also noted among respondents who spoke a language other than English at home, although a different pattern of responses emerged. This group did not perceive an attack to be more likely but did report high levels of concerns that they or family members would be directly affected by such attacks and had changed the way they lived as a result of this possibility. These respondents are more likely to represent minority linguistic/cultural groups and may possibly have experienced more recent migration. It is difficult to generalise, but higher apparent safety concerns may reflect different cultural mores about family protection among these respondents. In some cases, migration experiences or awareness of violence or terrorism in their countries of origin may also inform safety concerns and practices.

Common social reactions to threats, such as potential terrorism, may provide an alternative explanation. Threatening contexts are known to bias perceptual processes towards unfamiliar or potentially dangerous stimuli [20]. Increases in ethnocentrism and xenophobia have been observed at such times [21]. One survey shortly after the 2005 London bombing showed that the factor with the highest odds ratio for "substantial distress" $(\mathrm{OR}=4.0)$ was related to being Muslim [7]. Similarly, the current results may reflect minority group concerns about marginalisation associated with the emerging threat of terrorism. A corollary of this is that the recent practice within Australia of issuing public terror alerts and population-level information campaigns may actually increase the vulnerability of some sub-groups [22,23].

While LOTE respondents experienced significantly higher concern and changes in living, similar results were not observed in respondents born overseas more generally. It is likely that broad differences exist in the linguistic (and related cultural) practices of these sub-groups. Approximately $32 \%$ of Australian nationals who are born overseas migrate from English speaking countries (principally the United Kingdom, New Zealand and Canada), while 73\% of those from Non English speaking nations report high levels of proficiency in English [24]. Such factors may support greater assimilation of this group with the mainstream, nominally Anglo, culture of Australia. Conversely, language practices of LOTE respondents may serve to emphasise cultural differences which, at times of increased community apprehension, may also heighten concerns regarding cultural tolerance and discriminatory practices.

Most risk assessments identify major cities as the most likely targets of potential terrorist attack. In the current study this appears to have been reflected in heightened concerns of urban residents that they or family members would be directly affected should attacks take place. This is consistent with U.S. studies which showed that respondents perceived lower personal risk regarding terrorism the further they lived from major urban centres [5]. On this basis, it has been proposed that terrorism risk communication strategies be developed with distinct goals and messages for urban as opposed to rural residents [2].

It is noteworthy that high psychological distress did not emerge as a risk factor in the current multivariate analysis. 'Substantial distress' following terrorism has been linked with specific concerns and protective behaviours. It has been suggested that perceived coping abilities may be a key mediating factor [5]. In regions without recent terrorism less is known about the relationship between psychological distress and terrorism concerns; although a recent Australian study showed that a related domain, low personal well being, predicted high conviction that terrorism would occur [22]. The current findings may indicate that perceived terrorism threat was not sufficiently salient to be a focal concern for these individuals during the study period. However, this could also alter with changes in threat status. 
The finding that females are more willing to comply with evacuation has been observed elsewhere [25] and indicates that specifically engaging women as part of the risk communication and response may support high value outcomes. Having lower levels of education (middle school certificate) and speaking a language other than English at home were risk factors for lower willingness to evacuate public places or offices during terrorism emergencies. The latter finding seems inconsistent with the high levels of concern and changes in living reported by this group (albeit without perceived higher likelihood of terrorism). This reluctance to evacuate may reflect lower confidence regarding communication (i.e. receiving and recognising warnings) and an associated lower perceived ability to respond (self-efficacy) [25]. Other evidence indicates that the experiences of some ethnic minorities may contribute to their being less trusting of official disaster warnings and the bodies issuing these [26]. These findings warrant further study and highlight the need to ensure that potentially vulnerable groups are proactively accommodated in disaster planning and education.

A study of this type has several limitations. The response rate of $65 \%$ had the potential to introduce a response bias in relation to the current results. As noted, this was addressed by introducing weightings to adjust for probability of selection and for differing non-response rates among males and females and different age groups.

The question "Have you changed the way you live your life because of the possibility of a terrorist attack?" was intentionally broad, since current evidence indicates that preparatory changes for terrorism, in the absence of specific incidents, are limited and general in focus [15]. Adopting the full response set (a little, moderately, very and extremely) is likely to increase the sensitivity of this question to changes associated with public health messages or varied threat status over time. It is possible that more specific behaviours are being endorsed at the upper end of the range, with more subtle or even 'felt' changes being identified by a larger group at the lower end of the range.

\section{Conclusion}

The current results indicate that low education level is a risk factor for high terrorism risk perception and concerns regarding potential impacts. High levels of concern amongst those of migrant background, in the absence of high perceived terrorism likelihood, may reflect concerns regarding perceived marginalisation in the context of increased community threat; not the direct threat of terrorism itself. Public information campaigns regarding terrorism need to be framed so as to minimise the risk of exacerbating this social dynamic. Moreover, the identification of key risk groups through this study may support the development of group-specific risk communication strategies regarding terrorism threat and targeted messages to address their needs.

\section{Competing interests}

The authors declare that they have no competing interests.

\section{Authors' contributions}

BR and GS conceived the idea and designed the study. KA and GS carried out the statistical analysis. GS and KA wrote the manuscript. All authors made contributions to the interpretation of results and revised the manuscript for important intellectual content. All authors read and approved the final version of the manuscript.

\section{Acknowledgements}

This study was funded by Emergency Management Australia. This analysis is a part of the first author's thesis for a doctoral dissertation with the College of Health and Science at the University of Western Sydney. We would like to acknowledge the assistance of staff at the Centre for Epidemiology and Research, NSW Department of Health, for their help with data collection.

\section{References}

I. Marshall RD, Bryant RA, Amsel L, Suh EJ, Cook JM, Neria Y: The psychology of ongoing threat: relative risk appraisal the September II attacks and terrorism-related fears. Am Psychol 2007, 62(4):304-316.

2. Lemyre L, Lee JEC, Turner MC, Krewski D: Terrorism preparedness in Canada: a public survey on perceived institutional and individual response to terrorism. Int J Emergency Management 2007, 4(2):296-3I5.

3. Fischhoff B, Gonzales R, Small D, Lerner J: Evaluating the success of terror risk communications. Biosecur Bioterror 2003, I:255-258.

4. Schlenger WE, Caddell JM, Ebert L, Jordan BK, Rourke KM, Wilson D, Thalji L, Dennis JM, Fairbank JA, Kulka RA: Psychological reactions to terrorist attacks: findings from the National Study of Americans' Reactions to September II. JAMA 2002, 288:58I-588.

5. Silver RC, Holman EA, Mclntosh DN, Poulin M, Gil-Rivas V: Nationwide longitudinal study of psychological responses to September II. JAMA 2002, 288: I235-1244.

6. Torabi MR, Seo DC: National study of behavioural and life changes since September II. Health Educ Behav 2004, 31(2): 179-192.

7. Rubin G], Brewin CR, Greenberg N, Simpson J, Wessely S: Psychological and behavioural reactions to the bombings in London on 7 July 2005: cross sectional survey of a representative sample of Londoners. BMJ 2005, 331:606-6I2.

8. Gigerenzer G: Out of the frying pan into the fire: Behavioral reactions to terrorist attacks. Risk Anal 2006, 26(2):347-35I.

9. Rubin GJ, Brewin CR, Greenberg N, Hughes JH, Simpson J, Wessely $\mathrm{S}$ : Enduring consequences of terrorism: 7-month follow-up survey of reactions to the bombings in London on 7 July 2005. Br J Psychiatry 2007, 190:350-356.

10. Vlahov D, Galea S, Resnick H, Ahern J, Boscarino JA, Bucuvalas M, Gold J, Kilpatrick D: Increased use of cigarettes, alcohol, and marijuana among Manhattan, New York, residents after the September IIth terrorist attacks. Am J Epidemiol 2002, I 55( I I):988-996.

II. Boscarino JA, Figley CR, Adams RE: Fear of terrorism in New York after the September I I terrorist attacks: implications for emergency mental health and preparedness. Int J Emerg Ment Health 2003, 5(4): 199-209.

12. Boscarino JA, Adams RE, Figley CR, Galea S, Foa EB: Fear of terrorism and preparedness in New York City 2 years after the attacks: implications for disaster planning and research. J Public Health Manag Pract 2006, I 2(6):505-5I 3. 
13. Lemyre L, Lee JEC, Krewski D: National public survey of perceived CBRN terrorism threat and preparedness Ottawa: University of Ottawa, Institute of Population Health; 2004.

14. Lemyre L, Turner MC, Lee JEC, Krewski D: Public perception of terrorism threats and related information sources in Canada: implications for the management of terrorism risks. J Risk Res 2006, 9(7):755-774.

15. Transnational Terrorism: The Threat to Australia Department of Foreign Affairs \& Trade 2004 [http://www.dfat.gov.au/publica tions/terrorism/chapter2.html].

16. Barr M, Baker D, Gorringe M, Fritsche L: NSW Population Health Survey: Description of Methods. 2008 [http:// www.health.nsw.gov.au/resources/publichealth/surveys/ health survey method.asp].

17. Barr M, Raphael B, Taylor M, Stevens G, Jorm L, Griffin M, Lujic S: Pandemic influenza in Australia: using telephone surveys to measure perceptions of threat and willingness to comply. BMC Infectious Diseases 2008, 8: II7.

18. Kessler R, Mroczek D: Final Version: Non-specific Psychological Distress Scale [memo dated 10/3/94]. Ann Arbort (MI): Survey Research Center of the Institute for Social Research. University of Michigan; 1994.

19. Huddy L, Feldman S, Capelos T, Provost C: The consequences of terrorism: disentangling the effects of personal and national threat. Polit Psychol 2002, 23(3):485-509.

20. Liberman A, Chaiken S: Defensive processing of personally relevant health messages. Pers Soc Psychol Bull 1992, I 8:669-679.

21. Struch N, Schwartz SH: Intergroup aggression: its predictors and distinctness from in-group bias. J Pers Soc Psychol 1989 56:364-373.

22. Cummins RA: Australian Unity Wellbeing Index, Report I9.0, August 2008, Part A: The Wellbeing of Australians - Limited Release. 2008 [http://acqol.deakin.edu.au/index wellbeing/ Survey 19 Part A.pdf].

23. Tucker JB: Strategies for Countering Terrorism: Lessons from the Israeli Experience. Journal of Homeland Security 2003 [http:// homelandsecurity.org/journal/Articles/tucker-israel.html].

24. Australian Bureau of Statistics: Labour market outcomes of migrants. 2006 [http://www.abs.gov.au/AUSSTATS/abs@.nsf/Lat estproducts/F930564|43DFA8A8CA257IB000153DD7?opendocu ment]. Australian Labour Market Statistics, cat. no. 6105.0, ABS, Canberra

25. Kirschenbaum A: Warning and evacuation during a mass disaster: a multivariate decision making model. International J Mass Emergencies and Disasters 1992, I 0(I):9|-I |4.

26. Drabek TE: Understanding disaster warning responses. The Social Science Journal 1999, 36(3):515-532.

\section{Pre-publication history}

The pre-publication history for this paper can be accessed here:

http://www.biomedcentral.com/1471-2458/9/91/prepub
Publish with Bio Med Central and every scientist can read your work free of charge

"BioMed Central will be the most significant development for disseminating the results of biomedical research in our lifetime. "

Sir Paul Nurse, Cancer Research UK

Your research papers will be:

- available free of charge to the entire biomedical community

- peer reviewed and published immediately upon acceptance

- cited in PubMed and archived on PubMed Central

- yours - you keep the copyright
BioMedcentral 